\title{
CZU:633.15:631.52 https://doi.org/10.53040/gppb7.2021.67 \\ GERMOPLASMA DE PORUMB UTILĂ LA CREAREA LINIILOR CONSANGVINIZATE TIMPURII
}

\author{
Musteaţa Simion, Borozan Pantelimon, Spînu Valentina \\ Institutul de Fitotehnie „Porumbeni”, Pașcani, Republica Moldova \\ e-mail: pantelimon.borozan@yahoo.com
}

\begin{abstract}
The evolution of germplasm incorporated into 477 inbred lines of early maize developed in 19812019 years are presented here. It is concluded that for modern maize breeding more useful germplasm are alternative heterotic groups Euroflint mixt, Reid Iodent, BSSS-B37 and Lancaster. A comparative study of 20 inbred lines from 3 heterotic groups demonstrated the performance of Reid Iodent germplasm as seed, female parents. In the mentioned period 35 original inbred lines used as parents of registered hybrids have been created.
\end{abstract}

Key words: maize, agronomical characteristics, germplasm groups, hybrids, inbred lines.

\section{Introducere}

Valoarea liniilor consangvinizate de porumb în primul rând se asociază cu capacitatea lor de combinare şi caracteristicile agronomice, care contribuie la producerea de sămânţă hibridă [1]. Rezultatele experimentale ale ameliorării pe plan mondial au demonstrat că manifestarea heterozisului reproductiv la încrucişări între linii consangvinizate se datorează recombinărilor anumitor grupe de germoplasmă, desemnate şi ca grupe heterotice [2]. Analiza datelor experimentării hibrizilor a evidențiat cele mai performante grupe de germoplasmă, care în formulele de hibridare realizează producții superioare. În literatura de specialitate sunt descrise modelele heterotice de sintetizare dirijată a hibrizilor și de utilizare în procesul de creare a liniilor consangvinizate [3]. Menționăm că la porumbul timpuriu pentru zonele nordice cu regim termic deficitar au fost folosite modelele heterotice reprezentate de încrucișari a germoplasmei dentiformis american cu linii consangvinizate indurata [4]. Cercetările de clasificare a liniilor în grupe şi subgrupe heterotice în baza diferențierii după datele pedigreului, descriptorilor fenotipici, distanțării genetice în încrucișări și analizei markerilor moleculari au accelerat exploatarea surselor noi de germoplasmă și îmbunătățirea germoplasmei folosite anterior.

În prezenta lucrare este analizată evoluția principalelor surse de germoplasmă incluse în pedigreul liniilor experimentale din colecția operațională și valoarea lor agronomică.

\section{Materiale și metode}

În calitate de material biologic s-au folosit 477 linii consangvinizate originale incluse în colecția operațională a laboratorului ameliorării porumbului pentru zonele nordice în perioada 1981-2019 și utilizate ca forme parentale ale hibrizilor din culturi comparative avansate. Liniile respective au fost create prin metoda pedigreului, selecția fenotipică între descendențe și aprecierea capacității generale de combinare în încrucișări sistemice de tip topcross. Clasificarea liniilor în grupe de germoplasmă s-a efectuat în baza datelor genealogice, descrierii fenotipice comparativ cu mostrele de referință și a valorilor producției de boabe în încrucișări de analiză a diversității genetice. În procesul de evaluare a 11 indicatori agronomici s-au folosit 6 linii din grupa de germoplasmă Euroflint - MKP19A, MKP20, MKP21/182, MKP22, MKP27 şi AN615/95MRf, 8 linii cu germoplasmă Reid Iodent - MKP60, MKP601, MKP61, MKP611, MKP612, MKP63, MKP64, MKP65 și 6 linii din grupa heterotică BSSS-B37 - MKP70, MKP71, MKP711, AN1260/16, AN1262/16, AN1269/16. Principalele caracteristici ameliorative s-au studiat în culturi comparative de orientare pe parcele de $10 \mathrm{~m}^{2}$ x 2 repetiții. Boabele recoltate au fost separate după dimensiuni în 4 fracții, folosindu-se completul de site cu orificii rotunde de $9 \mathrm{~mm}$ (fracția 1), $8 \mathrm{~mm}$ (fracția 2), $7 \mathrm{~mm}$ (fracția 3), $6 \mathrm{~mm}$ (fracția 4) i-ar boabele mai mici de $6 \mathrm{~mm} \mathrm{~s}$-au considerat ca rebut. Germinația de câmp a semințelor netratate s-a apreciat pe parcele de $2,5 \mathrm{~m}^{2} \times 3$ repetiții semănate la sfârșitul lunii martie - epoca extratimpurie și începutul decadei a doua din aprilie - epoca timpurie. 


\section{Rezultate și discuții}

În perioada 1981-1990 în pedigreul liniilor consangvinizate predomina grupa de germoplasmă Dent mixt - 24,9\%, recombinată în hibrizi comerciali de origine străină, hibrizi cu 3-4 linii și populații sintetice cu bază genetică largă ca material inițial (tabelul 1).

Primele linii consangvinizate MKP33, MKP35 și MKP42 au fost realizate în baza hibrizilor firmei Pioneer din SUA - P3968, P3995 și X4758. O pondere relativ înaltă - 23,8\% revenea germoplasmei indurata Euroflint și Ottava flint, inclusiv 12,5\% grupei heterotice Lacaune cu linia indicatoare F2.

Tabelul 1. Cota germoplasmei de porumb în pedigreul liniilor consangvinizate din colecţia operaţională (în \%).

\begin{tabular}{|c|c|c|c|c|c|c|c|}
\hline $\begin{array}{l}\text { Nr. } \\
\text { d/or }\end{array}$ & $\begin{array}{c}\text { Grupa de } \\
\text { germoplasmă }\end{array}$ & $\begin{array}{c}\text { Linia } \\
\text { indicatoare }\end{array}$ & $\begin{array}{c}1981- \\
1990\end{array}$ & $\begin{array}{l}1991- \\
2000\end{array}$ & $\begin{array}{l}2001- \\
2010\end{array}$ & $\begin{array}{l}2011- \\
2019 \\
\end{array}$ & Linii în hibrizi omologaţi \\
\hline 1. & Euroflint & $\mathrm{F} 2$ & 12,5 & 14,5 & 9,8 & 1,6 & MKP16 \\
\hline 2. & Euroflint & EP1 & 2,8 & 2,4 & - & - & - \\
\hline 3. & Euroflint & DK105 & - & 2,4 & 3,3 & 3,2 & AN615/95 \\
\hline 4. & Ottava flint & CM7 & 2,8 & 1,6 & 1,6 & - & MKP126 \\
\hline 5. & Euroflint mixt & - & 5,7 & 8,1 & 15,6 & 23,8 & $\begin{array}{l}\text { MKP19A, MKP20, MKP21/182, MKP22, } \\
\text { MKH27, MKP27 }\end{array}$ \\
\hline 6. & Dent Canadian & Co72-75 & 4,8 & 1,6 & 2,5 & 0,8 & $1866 / 82$, MKP41 \\
\hline 7. & Dent Canadian & Co125 & 3,8 & 0,8 & - & - & MKP38 \\
\hline 8. & Dent Canadian & CG12 & 5,7 & 3,2 & 4,9 & 1,6 & MKP28, МKP36, MKP52, MKP52А \\
\hline 9. & Vigor & PLS61 & 2,8 & - & - & - & - \\
\hline 10. & Minnesota 13 & W401 & 1,9 & - & - & - & - \\
\hline 11. & $\begin{array}{l}\text { Northwestern } \\
\text { Dent }\end{array}$ & P354 & 2,8 & - & - & - & - \\
\hline 12. & Reid Wilson & A654 & 1,9 & 4,8 & - & - & - \\
\hline 13. & BSSS-B14 & CM174 & 17,2 & 17,7 & 4,1 & - & PT131, MKP33/1 \\
\hline 14. & Reid Iodent & P343 & 2,8 & 6,1 & 20,5 & 33,3 & $\begin{array}{c}\text { MKP60, MKP61, MKP601, MKP611, } \\
\text { MKP612, MKP63, MKP64 }\end{array}$ \\
\hline 15. & Lancaster & Mo17 & 3,8 & 5,5 & 6,6 & 12,7 & MKP56 \\
\hline 16. & Lancaster & $\mathrm{OH} 43$ & 1,9 & 4,8 & 4,9 & 5,6 & MKP55 \\
\hline 17. & BSSS-B37 & MK271 & 1,9 & 4,0 & 8,2 & 9,5 & MKP70, MKP71, MKP711 \\
\hline 18. & Dent mixt & - & 24,9 & 22,5 & 18,0 & 7,9 & MKP33, MKP35, MKP42, MKP47, MKP58 \\
\hline
\end{tabular}

Menționăm că germoplasma respectivă cu proveniență din zonele nordice cu regim termic deficitar s-a dovedit a fi mai slab adaptată la condițiile naturale ale Moldovei cu frecvente secete de sol și atmosferice. În procesul de creare a liniilor cu bob dentat în perioada respectivă intens a fost folosit materialul iniţial sintetizat în baza liniilor străine de circulaţie liberă A632, A634, A635, CM105 și CM174 incluse în grupa de germoplasmă BSSS-B14. Descendențele constante din colecția operațională cu o cotă de $17,2 \%$ se evidențiau prin multiple caracteristici ameliorative valoroase dar în combinaţii hibride au realizat producții de boabe medii, cu excepția liniilor PT131 și MKP33/1. Linia PT131 s-a constatat a fi mai performantă în încrucișări cu testeri de la SCDA Turda, România, fiind realizată ca formă paternă în hibridul comun Doina. Germoplasma liniilor consangvinizate Co72-75, Co125 și CG12 cu origine din Canada și clasificate în grupa convențională Dent Canadian s-a constatat a fi relativ adaptată la cadrul natural al Moldovei și cu performanțe după producția de boabe și masa de siloz în hibrizii testați în diverse localități ecologice din R. Belarus. Cu participarea acestor surse de germoplasmă s-au creat 7 linii originale utilizate ca forme parentale în hibrizii timpurii omologaţi, inclusiv Bemo 181CRf, Bemo 182CRf, Nemo 216CRf și Bemo 172CRf cu o pondere semnificativă în exportul seminţelor. Utilizarea surselor de germoplasmă Vigor, Minnesota 13, Northwestern Dent și Reid Wilson din grupa de maturitate FAO 250-300 a rezultat cu evidențierea unor linii experimentale cu o cotă sumară de 9,4\% în anii 1981 1990. Testările ecologice în R. Belarus a hibrizilor creați cu liniile din sursele menționate au constatat rezultate medii și mai joase după producția de boabe și substanță uscată a masei de siloz. Anumite avantaje comparativ cu martorii s-au sesizat la hibrizii cu liniile experimentale create în baza genitorilor A654 și P346 cu apartenenţă la grupa de germoplasmă Reid Wilson, care în următoarea perioadă au fost prezentate în colecția operațională cu o pondere de $4,8 \%$. 
După anul 1991 programul de creare a liniilor consangvinizate de porumb timpuriu a fost orientat spre grupele de germoplasmă mai tardive, folosite ca donatori de gene favorabile în încrucișări cu linii originale din grupele de maturitate FAO 160-240. La compartimentul porumbului cu bob sticlos materialul inițial a fost diversificat prin introducerea liniei DK105 creată din soiul german Gelber Landmais și a liniilor mai tardive F564 din grupa Lacaune, Lo3 extrasă din soiul italian Nostrano dell isola, Pi187 cu germoplasma soiului Morano și ИК169-3 din grupa Euroflint mixt. Adiţionarea genitorilor respectivi au rezultat cu dispariţia caracterelor fenotipice distinctive a surselor iniţiale de germoplasmă și în prezent liniile noi originale sunt clasificate în complexul convențional Euroflint mixt, reprezentat de 6 linii folosite în componența hibrizilor omologați. Ca germoplasmă distinctă, sub aspect fenotipic și genetic, rămâne linia comercială AN615/95, care datorită prezenței genelor de restaurare a fertilității polenului în citoplasmă androsterilă de tip C este folosită doar ca formă paternă în hibrizii extratimpurii FAO 160-190. Selecția fenotipică pe parcursul a mai multor cicluri consecutive de ameliorare a liniilor consangvinizate a înregistrat un progres genetic semnificativ după adaptabilitatea ecologică, rezistența la frângere a tulpinii, toleranței la patogenii tăciunelui comun și prăfos, caracterul stay green la plantă după maturitatea fiziologică. Un obiectiv primordial în ultima etapă de ameliorare a devenit îmbunătăţirea capacității generale și specifice de combinare, însuşire mai slab pronunţată la porumbul cu bob sticlos. În perioada 2001-2019 semnificativ s-a majorat ponderea germoplasmei Reid Iodent, dezvoltată de amelioratorii firmei Pioneer Hi-Bred și îmbunătățită în peste 10 cicluri de selecție cumulativă. Ca genitori în materialul iniţial s-au folosit liniile elită P101, P343, P165 - firma Pioneer, SUA, MK01, MK276, AS587/02 create în Moldova și GK26. DK205/710, DK437 din Ucraina. La precocizarea materialului de selecție au fost folosite liniile experimentale timpurii extrase din populația sintetică MKP33 și donatorul semitimpuriu D29. Cele 7 linii originale, atribuite la grupa heterotică Reid Iodent, au fost folosite ca forme materne în 9 hibrizi de porumb omologați după anul 2012 în Belarus, Rusia, Kazahstan, Ucraina, România și Moldova. Lucrările de precocizare a germoplasmei grupelor heterotice Lancaster și BSSS-B37 au rezultat cu o majorare a contribuției acestora în pedigreul liniilor consangvinizate din colecția operațională până la $27,8 \%$ și crearea a 5 linii utilizate în hibrizi comerciali. Testările hibrizilor experimentali în condițiile Moldovei și Belarus au constatat performanțe superioare a liniilor din grupa BSSS-B37 comparativ cu germoplasma Lancaster, subgrupa Mo17. Liniile originale MKP70, MKP71 și MKP711 au fost create din materialul iniţial cu genitorii MK271, D27 și OH43, care au fost transferate la restaurarea fertilitătii polenului în citoplasmă androsterilă de tip M. Grupa Dent mixt cu o pondere de la $24,9 \%$ până la $7,9 \%$ include în prezent liniile consangvinizate dezvoltate din hibrizii comerciali a firmelor străine cu anumite caractere distincte.

Tabelul 2. Caracteristicile ameliorative ale liniilor consangvinizate din 3 grupe heterotice alternative (media 2016-2019)

\begin{tabular}{|c|c|c|c|c|c|c|c|}
\hline \multirow{2}{*}{$\begin{array}{c}\mathrm{Nrd} / \\
\mathrm{o}\end{array}$} & \multirow[t]{2}{*}{ Caracteristicile ameliorative } & \multicolumn{2}{|c|}{ Euroflint } & \multicolumn{2}{|c|}{ Reid Iodent } & \multicolumn{2}{|c|}{ BSSS-B37 } \\
\hline & & media & $\min -\max$ & media & $\min -\max$ & media & $\min -\max$ \\
\hline 1. & $\begin{array}{l}\text { Ritm de creştere în faza de 5-7 } \\
\text { frunze, nota }\end{array}$ & 7,8 & $6,5-8,6$ & 7,2 & $6,2-8,1$ & 7,7 & $7,0-8,2$ \\
\hline 2. & $\begin{array}{l}\text { Perioada „răsărit-apariţia } \\
\text { stigmatelor”, zile }\end{array}$ & 59,1 & $56,8-61,6$ & 62,3 & $59,5-63,4$ & 60,9 & $58,6-63,0$ \\
\hline 3. & Producția de boabe, $\mathrm{t} / \mathrm{ha}$ & 2,234 & $1,658-2,710$ & 3,428 & $2,704-4,592$ & 3,064 & $2,045-4,190$ \\
\hline 4. & Umiditatea boabelor, \% & 13,9 & $12,5-14,6$ & 12,8 & $12,0-13,3$ & 13,2 & $12,3-13,9$ \\
\hline 5. & Masa a 1000 boabe, $\mathrm{g}$ & 188,7 & $170,5-195,7$ & 206,8 & $198,4-219,7$ & 202,5 & $196,8-210,7$ \\
\hline 6. & $\begin{array}{l}\text { Cota fracţiilor de seminţe cu } \\
\text { dimensiuni medii, \% }\end{array}$ & 54,8 & $31,6-57,8$ & 75,6 & $71,8-77,4$ & 70,2 & $68,9-74,6$ \\
\hline 7. & Plante atacate cu tăciune comun, \% & 1,7 & $0,6-2,6$ & 1,1 & $0,4-1,9$ & 2,3 & $0,6-3,4$ \\
\hline 8. & Plante atacate cu tăciune prăfos, $\%$ & 0,6 & $0,0-1,2$ & 1,2 & $0,5-2,1$ & 3,6 & $0,9-4,5$ \\
\hline 9. & Cota plantelor frânte, $\%$ & 2,2 & $0,6-3,9$ & 0,5 & $0,0-1,2$ & 1,3 & $0,0-2,6$ \\
\hline 10. & $\begin{array}{l}\text { Germinaţia seminţelor semănate în } \\
\text { epoca extratimpurie, \% }\end{array}$ & 58,2 & $54,8-60,7$ & 48,9 & $27,3-59,0$ & 50,6 & $46,1-59,7$ \\
\hline 11. & $\begin{array}{l}\text { Germinaţia seminţelor semănate în } \\
\text { epoca timpurie, } \%\end{array}$ & 76,4 & $72,8-78,4$ & 67,3 & $41,8-71,2$ & 70,9 & $68,4-72,6$ \\
\hline
\end{tabular}


Rezultatele studiului comparativ a 20 linii consangvinizate din 3 grupe alternative de germoplasmă pe parcursul anilor 2016-2019 atestă pretabilitatea grupei Reid Iodent ca forme materne în combinații hibride. Dintre caracteristicile cu impact pozitiv în producerea semințelor, menționăm producția de boabe mai ridicată - 3,428t/ha, masa a 1000 boabe - 206,8g și cota fracţiilor de semințe cu dimensiuni medii 75,6\% (tabelul 2).

Un alt element important se referă la menținerea perfectă a androsterilității citoplasmatice de tip M, care permite producerea de semințe în baza sistemului genetic cms-Rf. Grupa Euroflint cu o toleranţă mai înaltă la temperaturile joase ale solului în perioada de germinare a semințelor dar cu un potențial inferior al producției de boabe - 2,234t/ha și dimensiuni mai mici a boabelor mai bine se încadrează în calitate de forme paterne. Liniile consangvinizate originale cu germoplasma grupei heterotice BSSS-B37 pot fi folosite în combinații hibride în ambele poziții. Prin urmare, în procesul de sintetizare a hibrizilor timpurii utile sunt modelele heterotic Reid Iodent x Euroflint, BSSS-B37 x Euroflint și Reid Iodent x BSSS-B37 în formula de hibridare directă și inversată. Germoplasma subgrupei Mo17 a înregistrat o creștere semnificativă în pedigreul descendențelor constante din colecția operațională, urmând a fí verificată după potențialul de producție în hibrizi.

\section{Concluzii}

1. Analiza pedigreului a 477 linii consangvinizate de porumb timpuriu, transferate în colecția operațională în perioada anilor 1981-2019, atestă schimbări esenţiale a cotei germoplasmei utilizate în lucrările de selecție şi dispariţia unor grupe heterotice importante în ameliorarea porumbului în secolul trecut.

2. Precocizarea liniilor elită tardive din grupa Reid Iodent a majorat semnificativ ponderea acesteia în liniile consangvinizate moderne cu performanțe agronomice și capacitate de combinare înaltă. Germoplasma respectivă predomină în formele materne ale hibrizilor omologați datorită unor caracteristici cu impact pozitiv în producerea seminţelor.

3. Germoplasma subgrupelor Mo17 și OH43 din Lancaster și a grupei BSSS-B37 cu o pondere sumară de circa $18 \%$ în liniile experimentale, prezintă surse utile pentru crearea liniilor consangvinizate ca forme paterne ale hibrizilor de porumb timpuriu.

\section{Bibliografie}

1. HAȘ, IOAN. 2004, Heterozisul la porumb. În "Porumbul, Studiul monografic", Ediția Academiei Române, București, p. 311-362.

2. HALLAUER, A. R., MIRANDA, J.B. 1981, Quantitative genetics in maize breeding. Iowa State University Press, Ames,

3. TROYER, A. F. 2000, Temperate corn. Background, behavior and breeding. In "Speciality Corn. Second edition", CRC Press, USA, p.393-466.

4. MUSTEAȚA, S. 2008. Sursele de germoplasmă utilizate în ameliorarea porumbului timpuriu. În "Agrobiodiversitatea vegetală a R. Moldova: evaluarea, conservarea și utilizarea”, Chișinău, p. 83-88. 